Citation: Enrique Orduña-Malea, Cristina I. Font-Julián, José Antonio Ontalba-Ruipérez, Raúl Compés-López (2021) Masters of Wine on Twitter: presence, activity, impact and community structure. Wine Economics and Policy 10(1): 73-88. doi: 10.36253/wep-9055

Copyright:@2021 EnriqueOrduña-Malea, Cristina I. Font-Julián, José Antonio Ontalba-Ruipérez, Raúl CompésLópez. This is an open access, peerreviewed article published by Firenze University Press (http://www.fupress. com/wep) and distributed under the terms of the Creative Commons Attribution License, which permits unrestricted use, distribution, and reproduction in any medium, provided the original author and source are credited.

Data Availability Statement: All relevant data are within the paper and its Supporting Information files.

Competing Interests: The Author(s) declare(s) no conflict of interest.

\section{Masters of Wine on Twitter: presence, activity, impact and community structure}

\author{
Enrique Orduña-Malea ${ }^{1, *}$, Cristina I. Font-Julián ${ }^{1}$, José Antonio \\ Ontalba-RuipéreZ ${ }^{1}$, RAúl COMpÉS-LÓPEZ ${ }^{2}$ \\ ${ }^{1}$ Universitat Politècnica de València, Department of Audiovisual Communication, Docu- \\ mentation and History of Art, Spain \\ ${ }^{2}$ Universitat Politècnica de València, Department of Economy and Social Sciences, Spain \\ E-mail: enorma@upv.es; crifonju@upv.es; joonrui@upv.es; rcompes@esp.upv.es \\ ${ }^{\star}$ Corresponding author.
}

\begin{abstract}
Globalisation, the Internet and social media have changed the kind of actors with influence in the wine industry and the way these actors create signals to communicate credible information about experience and trust attributes. Among the most prestigious experts in the world of wine are the Masters of Wine (MW). Although initially devoted to international trade, they have spread their activities and their opinion is more and more appreciated by producers and consumers. The main objective of this article is to determine this community of experts' behaviour on Twitter. In order to do so, four factors (presence, activity, impact and community) have been considered. All Twitter profiles belonging to users awarded with the MW qualification were identified and analysed. In addition, a set of 35,653 tweets published by the MWs were retrieved and analysed through descriptive statistics. The results show MWs on Twitter as high attractors (number of followers), moderate publishers (original contents published), moderate influencers (number of likes and retweets), and low interactors (number of friends and mentions to other users). These findings reveal that the MW community is not using Twitter to gain or reinforce their reputation as an accredited expert in the wine industry, giving more influential space on Twitter to consumers and amateurs.
\end{abstract}

Keywords: wine, wine industry, wine experts, social media, Twitter, Informetrics.

\section{INTRODUCTION}

Wine has experience and trust attributes that ask for signals to avoid market failures. The role of critics, guides, prizes, awards and other thirdparty references has always been important to offer market actors credible information about the characteristics of wine [17, 32]. The globalisation of wine markets has increased the supply of wine and, consequently, the need of this kind of information for consumers.

The emergence of the Internet and the development of social networks changed the way people receive and interchange information [9], emerging thus new influence models where new actors can provide information and 
influence market trends, therefore increasing the options to search and transmit signals of quality [32].

In particular, the potentiality of Twitter to generate influence has been widely proved [6]. Previous findings suggest that Twitter can create soft value for wine focused businesses [43]. However, more engagement from wine actors (marketers, brands, retailers, etc.) with those consumers talking about wine on Twitter is needed to create hard value.

Among the emerging actors who can play a role within the online conversation are the Masters of Wine (MW). The MW certification is the most prestigious in the world of wine for trade purposes. There are currently 384 MWs worldwide-out of the 452 that have obtained the certificate since its founding in 1953-from 30 different countries, although the most important group is that from Anglo-Saxon countries. All of them have a great reputation and hold important responsibilities in the different organisations that make up the global wine system. In general, most of them are opinion makers, although some of them have greater public presence, depending on their main activity. Their sound knowledge and prestige make of them potential wine critics and influencers.

The objective of this work is to identify and characterise the behaviour of the community of the Masters of Wine on Twitter, as well as to determine the impact achieved by these reputable wine experts through this platform. This understanding will allow further research in the field of 'wine and expert opinion' to be developed, identified by Storchmann [36] as one of the most important in wine economics.

There is a considerable amount of literature regarding the world of wine and the impact of gurus, experts and critics, both through publications and specialised magazines $[2,4,13,27]$, as well as blogs and social networks $[8,26]$. The influence of certain professionals, such as sommeliers, who have a direct relationship with the final consumer and clients, has also been investigated $[20,34]$. However, there are no studies - neither online nor offline - that analyse the role played by prestigious qualifications or diplomas, such as the MW, which enhance the reputation or brand of those who obtain them.

This is probably due to the difficulty of measuring the real influence - or capacity of influence - of such a large and heterogeneous group, where graduates carry out various professional activities (many make wine, others blend it, others buy it, others trade it, some teach it, and others write about it). This means that in some cases their influence is direct while in others it is indirect. In some cases, their influence is very intense, and in others it is practically non-existent. The approach of this article is therefore original, as it aims to estimate the behaviour of all the professionals with this qualification through participation as members of the social network Twitter, which serves as an indicator of their influence.

\section{LITERATURE REVIEW}

Social media's interactivity has empowered wine consumers to influence others [43], enhancing the role of crowdsourcing amateur opinions in areas traditionally relegated to experts [1]. Users can comment, review and share information online on the one hand, and search for this information as part of the consumption experience on the other hand [11]. Consequently, the online community has created a force within the industry [29], and has become one of the trust factors than can increase selling of products online [37], which is particularly effective among wine consumers, as word of mouth is such an important driver of wine sales [24].

The body of literature on wine and social media covers a wide variety of fields, mainly drinking alcohol (health), economics (sales and costs) and marketing (consumer behaviour and tourism) [25]. The latter concerns unveiling how wineries use social media for their business interests [32] and how marketers can use these tools to build a brand community [23].

Thach [38] coined the term Wine 2.0 and investigated to what extent wineries were adopting Web 2.0 components (mainly blogs and social media) as part of their marketing strategy and as potential accepted sources of information that might influence a purchasing decision, as well as increasing sales and consumption [40].

Facebook stands out as the most used social networking site regardless of the analysed country, followed by Twitter [37]. However, Instagram is increasing in some countries, such as Greece $[18,19]$. Nonetheless, studies from the consumers' perspective are scarce. Literature confirms that consumers who claim to use social media more intensively when collecting information about wine show a greater propensity to buy wine online $[25,32,35,39]$.

The conversational and informational nature of Twitter makes this tool of special interest to track user interest on specific products $[3,5,12]$, especially for marketing purposes $[10,21]$ and expert finding [42].

Wilson and Quinton [43] analyse a collection of tweets in English on the subject of wine in order to identify how wine was being discussed. An international 
and diverse tweeting population with interest in the consumption of wine was discovered, where the interactive medium (Twitter) had empowered the consumer to influence others, irrespective of any existing relationship. Contrary to what happens with wine experts and critics in traditional specialised magazines, wine industry professionals do not control the ability of Twitter users to have peer influence because of their independent Twitter status.

Specifically, Wilson and Quinton [43] find wine bloggers as active and influential actors. According to Wright [44], 84\% of wine bloggers use Twitter to promote their blogs. This community of bloggers can be divided into those who have no professional affiliation to the wine industry, entrepreneurial wine bloggers promoting their company, and other bloggers strongly connected to the wine industry and/or press, such as Robert Parker [16].

Marlowe et al. [26] analyse a sample of wine bloggers on Twitter in order to determine whether users with wine credentials attract more Twitter followers, as a proxy of becoming an influential voice on Twitter. To do this, the authors take into account the following nationally and globally-respected certifying bodies for wine credentialing: The Court of Master Sommeliers, Wine and Spirit Education Trust (WSET), Society of Wine Educators, Culinary Institute of America, International Sommelier Guild, Sommelier Society of America, and the International Wine Guild. The analysis concluded that wine bloggers with a certification had on average $75 \%$ more followers than those without certifications, supporting prior research showing that credentials have a major influence on others' behaviour [26].

Masters of Wine, irrespective of their specific connection with the wine industry, might establish a reputation and authority on Twitter, as wine expert users having a wine credential. However, this community has not been studied to date. Therefore, this contribution aims to fill this gap in the literature and provide a better understanding of this community, especially its online visibility and impact on Twitter, with the aim of providing wine market research practitioners a basis on which to better develop their work.

\section{METHOD}

Twitter is widely used as a data source for research since its inception [31,45]. Taking apart conceptual and technical aspects, research based on Twitter data focuses on two elements: users and contents, shaped by a specific domain [41]. In this article, these elements are framed by the Masters of Wine (users), all those contents generated by this community on Twitter (messages), and the wine market (domain).

The behaviour in general - and influence degree in particular - of one user is delimited consequently by the contents generated and the impact of these contents on other users, considering the characteristics of the analysed domain. Notwithstanding, there is no consensus on what specifically denotes influence on Twitter.

Literature has led to the conclusion that each approach to determine 'influence' depends on the emphasis on different individual factors [3]. We can find factors related to connectivity (followers), contentoriented interactions (replies, mentions), click-oriented interactions (retweets, likes), and network-oriented measures (centrality metrics). Moreover, these measures are diverse. Some are based on simple metrics provided by the Twitter API, while others are based on complex mathematical models [33]. In addition, some approaches are based on the combination of several metrics to generate a final score, while other approaches try to reflect influence through each of the metrics measured separately [30].

For this exploratory study, four behaviour and influence factors have been considered:

1. Presence. This factor considers whether a MW has created a public Twitter profile. For each profile created, this factor includes all demographic user-level information incorporated into the profile.

2. Activity. This factor considers to what extent are MWs creating content on Twitter, and it includes productivity and types of content created.

3. Impact. This factor considers to what extent are MWs engaging with users, and it includes metrics related to connectivity and interactions, both content-oriented and click-oriented.

4. Community. This factor considers to what extent do MWs communicate with other MWs on Twitter, and it includes network-oriented interactions.

The approach followed by this work does not emphasise any of the factors considered, nor does it intend to generate an influence on the final score, but describe the overall behaviour of MWs on Twitter just as a preliminary stage to characterise their influence.

The first step consisted of gathering the population of professionals awarded with the MW distinction to date. To do this, the Institute of Masters of Wine's official website ${ }^{1}$ was directly accessed on 8 March 2019. A total of 384 people were gathered, along with basic descriptive data: country of residence, gender, pro-

\footnotetext{
${ }^{1}$ https://www.mastersofwine.org/en/meet-the-masters/Browse-by-
} region/browse-by-country-of-residence.cfm 
fession, personal website, and year in which she/he obtained the qualification.

Then, we proceeded to locate the MWs' personal profiles on Twitter. In order to do this, several searches by name/surname were carried out in the Twitter search box. In addition, the Institute of Masters of Wine offcial Twitter account ${ }^{2}$ was analysed to check followers/ following users and Twitter mentions. Finally, the MWs' personal websites were also consulted. At the end of the process, 186 Twitter accounts were identified.

The second step consisted of extracting data from each of the 186 Twitter accounts. This process was separated into two levels: profile-level data and publicationlevel data.

a) Profile data: information related to the overall Twitter account performance was gathered through the Twitter API as of 12 May 2019. The following metrics were captured for each profile: name, screen name, user ID, profile creation date, number of followers, followings and favourites, total number of tweets published, date of the first tweet, date of the last tweet, number of lists where the user is listed, language, bio text, location and personal URL.

In addition, the Social Authority of each profile was obtained from Followerwonk ${ }^{3}$, a professional suite oriented to analyse Twitter followers. This metric recursively measures the prestige of a Twitter account based on the prestige of the followers who follow said account. Social Authority metric scores from 0 (no authority) to 100 (maximum authority).

b) Publication data: all tweets published by all 186 Twitter accounts from October 2018 to April 2019 (seven months) were retrieved through the Twitter API. A total of 35,653 tweets were obtained. For each tweet, the following information fields were identified: tweet ID, tweet text, tweet author, publication date, number of favourites received, number of retweets received, language, type of tweet (original, reply, retweet) and embedded elements (media, URLs, hashtags and user mentions).

The third step consisted of quantifying the degree of interaction between MWs on Twitter through centrality measures. All mentions from each MW to any other MW were gathered, and a network was built with Gephi ${ }^{4}$. Finally, both node-level metrics (degree and centrality) and network-level metrics (density, diameter and average degree) were calculated to determine centrality measures [7]. Table 1 includes each of the metrics captured as well as their scope.

\footnotetext{
${ }^{2} \mathrm{https}: / /$ twitter.com/mastersofwine

${ }^{3}$ https://followerwonk.com/social-authority

${ }^{4} \mathrm{https} / /$ gephi.org
}

Table 1. Summary of network metrics used: level and scope.

\begin{tabular}{|c|c|c|}
\hline Metric & Level & Scope \\
\hline InDegree & Node & $\begin{array}{l}\text { The number of edges (mentions) directed } \\
\text { into a node (user) in a directed graph. In } \\
\text { this case, the number of mentions a MW } \\
\text { receives from other MWs }\end{array}$ \\
\hline OutDegree & Node & $\begin{array}{l}\text { The number of edges (mentions) directed } \\
\text { out of a node (user) in a directed graph. } \\
\text { In this case, the number of mentions a } \\
\text { MW provides to other MWs }\end{array}$ \\
\hline Degree & Node & $\begin{array}{l}\text { InDegree + OutDegree. In this case, this } \\
\text { measure represents the total number of } \\
\text { mentions where a MW is involved. }\end{array}$ \\
\hline $\begin{array}{l}\text { Eigenvector } \\
\text { centrality }\end{array}$ & Node & $\begin{array}{l}\text { A high eigenvector score means that } \\
\text { a node (user) is connected to many } \\
\text { nodes (users) who themselves have high } \\
\text { scores and vice versa. This metric is also } \\
\text { referred to as prestige score. }\end{array}$ \\
\hline Density & Network & $\begin{array}{l}\text { The number of connections the network } \\
\text { has, divided by the total possible } \\
\text { connections the network could have. }\end{array}$ \\
\hline Diameter & Network & $\begin{array}{l}\text { The shortest distance between the } \\
\text { two most distant nodes (users) in the } \\
\text { network. It denotes the number of steps, } \\
\text { on average, it takes to get from one } \\
\text { member of the network to another. }\end{array}$ \\
\hline Averą & et & $\begin{array}{l}\text { The average number of edges (mentions) } \\
\text { per node (users) in the network. }\end{array}$ \\
\hline
\end{tabular}

\section{RESULTS}

\subsection{Presence}

186 MWs out of the total 384 people awarded with such distinction (48.4\%) have a Twitter profile, 106 women $(57 \%)$ and 80 men (47\%). Of these, eight accounts (5 males and 3 females) exhibited no data. Therefore, the final sample was composed by 178 Twitter profiles.

The percentage of MWs with a Twitter profile increases according to the decade in which the person was awarded the qualification. $73.4 \%$ of people awarded the qualification during the 2010' decade have a Twitter profile (Table 2).

Most accounts were created between 2009 and 2014 (91\%). Eight users created the Twitter profile the same year they finished the study programme, while 77 already had a Twitter account when they obtained the qualification.

$58.4 \%$ of users included the term ' $M W$ ' in their profile name whereas $25.8 \%$ included the term as part of their username (name of the account after the @ symbol), reflecting personal branding purposes.

As regards the language used, a predominance of English (predefined for 169 accounts) was found, fol- 
Table 2. Number of Masters of Wine with a Twitter profile, broken down by decade of admission.

\begin{tabular}{lccc}
\hline & & \multicolumn{2}{c}{ Twitter } \\
\cline { 3 - 4 } Decade & MW & Yes & No \\
\hline $1950^{\prime}$ & 7 & 0 & $100 \%$ \\
$1960^{\prime}$ & 12 & 0 & $100 \%$ \\
$1970^{\prime}$ & 25 & $8 \%$ & $92 \%$ \\
$1980^{\prime}$ & 33 & $18.2 \%$ & $82 \%$ \\
$1990^{\prime}$ & 110 & $36.4 \%$ & $64 \%$ \\
$2000^{\prime}$ & 71 & $63.4 \%$ & $37 \%$ \\
$2010^{\prime}$ & 124 & $73.4 \%$ & $27 \%$ \\
\hline TOTAL & 382 & $48.2 \%$ & $51.8 \%$ \\
\hline
\end{tabular}

Source: Twitter. Note: data of completion date were unavailable for two Masters of wine.

lowed by Spanish (three accounts) and then Norwegian, Dutch, Swedish, Japanese, French and German (one account each). This bias towards English is a consequence of the origins of the MWs: 206 (53.6\%) come from the United Kingdom, 52 (13.5\%) from the United States and 24\% (6.25\%) from Australia (Table 3). The number of MWs from New Zealand, Ireland, and Cana$\mathrm{da}(26 ; 6.8 \%)$ is also significant.

No location data was found for 46 users (38 had the location field empty and six accounts included other information instead of a real/accurate location). Moreover, a location mismatch (different real origin and Twitter location) was detected for ten accounts. The geographies of MWs thus changes under the lens of Twitter (Figure 1).

Table 3. Ranking of countries according to the number of Masters of Wine.

\begin{tabular}{lccc}
\hline \multirow{2}{*}{ Country } & \multicolumn{2}{c}{ All MW } & \multicolumn{2}{c}{ MW on Twitter } \\
\cline { 2 - 4 } & Real Location & Real location & Twitter location \\
\hline United Kingdom & 206 & 80 & 54 \\
United States & 52 & 34 & 29 \\
Australia & 24 & 13 & 11 \\
France & 17 & 6 & 4 \\
New Zealand & 13 & 9 & 5 \\
Germany & 8 & 4 & 3 \\
Ireland & 7 & 7 & 6 \\
Canada & 6 & 2 & 2 \\
Spain & 6 & 5 & 3 \\
Norway & 5 & 2 & 1 \\
Switzerland & 5 & 1 & 1
\end{tabular}

Source: The Institute of Masters of Wine and Twitter.

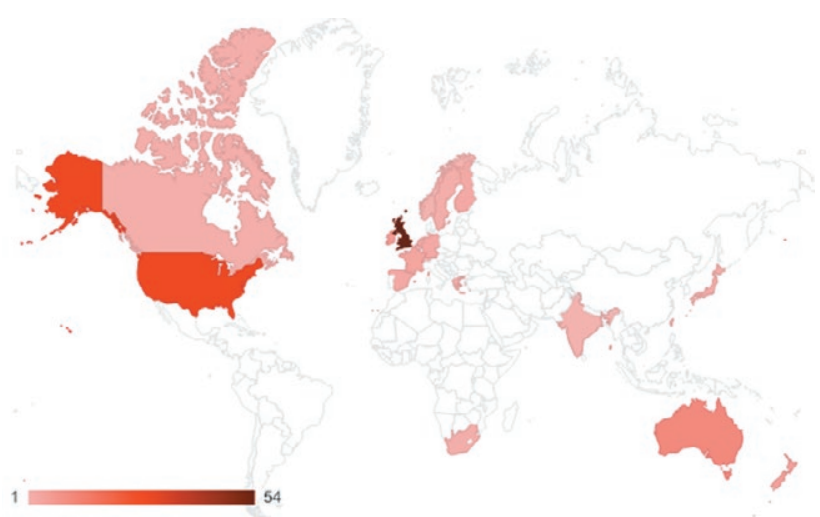

Figure 1. Masters of Wine according to the Twitter location field. Source: Twitter.

Users can include in their Twitter profiles a hyperlink to promote their related websites. 115 (61.8\%) users included a link, mainly to private companies (46) and personal websites (40). Other less common websites were personal blogs (9), media (5), searchers (2), LinkedIn profiles (2), YouTube profiles (1) and non-profit organisations (1). Also noteworthy is that nine links were broken, reflecting carelessness on the part of these users.

\subsection{Activity and impact}

For the sake of clarity, activity (contents generated) and impact (content outcome) influence factors are included together in this section, which starts with metrics related to the users (profile-level data) and follows with metrics related to the tweets (publication-level data).

\section{Profile-level data (users)}

No general patterns were found regarding the activity of the MWs on Twitter (Table 4). Data is widely dispersed and several outliers (both high and low performers) exist. However, on average, profiles attract a great number of followers (4,946 followers), although their productivity $(3,114$ tweets on average) and impact (2,159 favourites on average) is less intense. In addition, MWs did not usually follow other users (912 followings on average) and are included in few users' lists (119 lists on average).

The distribution of followers per user is highly skewed (Figure 2; top left). 17 users attained less than 100 followers while 12 users attracted more than 10,000 followers each. Jancis Robinson is the MW with the most followers $(257,031)$.

The number of followings is rather more homogeneous (Figure 2; top right) and exhibits lower values (only 
Table 4. General activity and impact patterns of Masters of Wine on Twitter.

\begin{tabular}{|c|c|c|c|c|c|c|c|}
\hline Statistic & Tweets & $\begin{array}{c}\text { Tweets/ } \\
\text { Day }\end{array}$ & Followers & $\begin{array}{c}\text { Followers/ } \\
\text { Day }\end{array}$ & Following & Favourites & Lists \\
\hline \multirow[t]{2}{*}{$\overline{M a x}$} & 60,856 & 14.9 & 257,031 & 70.3 & 12,702 & 89,109 & 3,757 \\
\hline & $\begin{array}{l}\text { Paul } \\
\text { Tudor }\end{array}$ & $\begin{array}{l}\text { Paul } \\
\text { Tudor }\end{array}$ & $\begin{array}{c}\text { Jancis } \\
\text { Robinson }\end{array}$ & Jancis Robinson & $\begin{array}{l}\text { Sarah } \\
\text { Abbott }\end{array}$ & $\begin{array}{l}\text { Paul } \\
\text { Tudor }\end{array}$ & $\begin{array}{c}\text { Jancis } \\
\text { Robinson }\end{array}$ \\
\hline 1st Quartile & 242.3 & 0.1 & 589.0 & 0.2 & 157.0 & 26.8 & 23.0 \\
\hline Median & 987.5 & 0.3 & $1,476.0$ & 0.5 & 359.5 & 223.0 & 45.0 \\
\hline 3rd Quartile & $3,019.8$ & 1.0 & $3,658.3$ & 1.3 & 990.3 & $1,377.8$ & 108.5 \\
\hline Mean & $3,113.6$ & 1.0 & $4,945.7$ & 1.5 & 911.5 & $2,159.3$ & 118.8 \\
\hline Standard deviation & $6,816.5$ & 2.0 & $20,303.7$ & 5.6 & $1,646.1$ & $9,057.4$ & 324.2 \\
\hline
\end{tabular}

Source: Elaborated from Twitter data. Note 1: data includes all activity generated by each Twitter account since its creation. Note 2: lists refer to the number of times that a user has created a list in which the user is included.

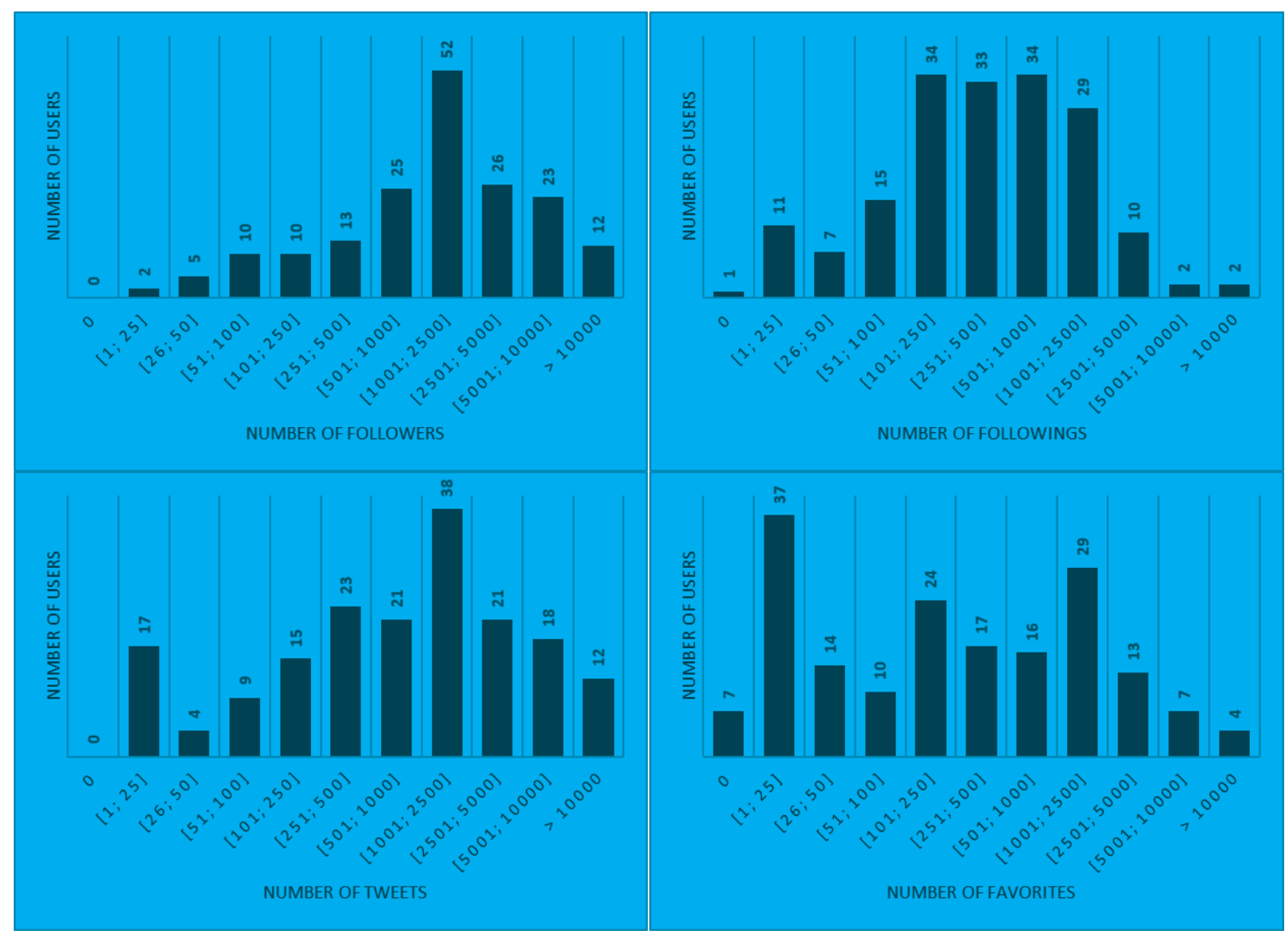

Figure 2. General behaviour of Masters of Wine on Twitter: distribution of followers (top left), followings (top right), tweets (bottom left) and favourites (bottom right). Source: Twitter.

12 MWs follow more than 2,500 users). It is noteworthy to mention that $30 \mathrm{MWs}$ have published less than 100 tweets (Figure 2; bottom left), and 68 (36.6\%) received less than 100 favourites (Figure 2; bottom right).
The number of followers achieved is not important in itself if we do not evaluate the quality of these followers. Thousands of inactive followers do not provide impact while hundreds of active and influential followers 


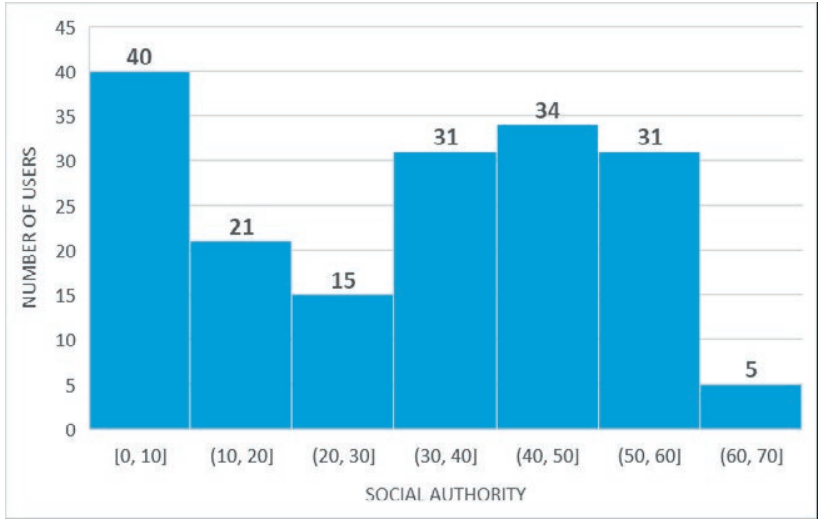

Figure 3. Social authority of Masters of Wine. Source: Followerwonk.

may provide reputation. The Social Authority indicator precisely measures this facet.

The average Social Authority for all MWs is 31.1 (32.0 in the case of female users and 30.1 for male users). Only five users surpassed the value of 60 . Tim Atkin stands out as the MW with the highest Social Authority (67). On the contrary, 40 users did not exceed the value of 10 (Figure 3).

Time elapsed since the creation of the Twitter account may distort the analysis, insomuch as one user may have more time to publish more Tweets and to obtain a better reputation. In order to check whether this parameter influences the remaining variables, a correlation test (Spearman) was performed (Table 5).

Age (the number of days since the creation of each Twitter profile) does not correlate strongly with any of the variables. As we can observe, the Social Authority achieves a strong correlation either with the number of favourites (Rs $=0.83$; p-value $<0.0001$ ) and tweets published $(\mathrm{Rs}=0.75$; $\mathrm{p}$-value $<0.0001)$, while the raw number of followers is slightly less important $(\mathrm{Rs}=0.65$; $\mathrm{p}$-value $<0.0001$ ).

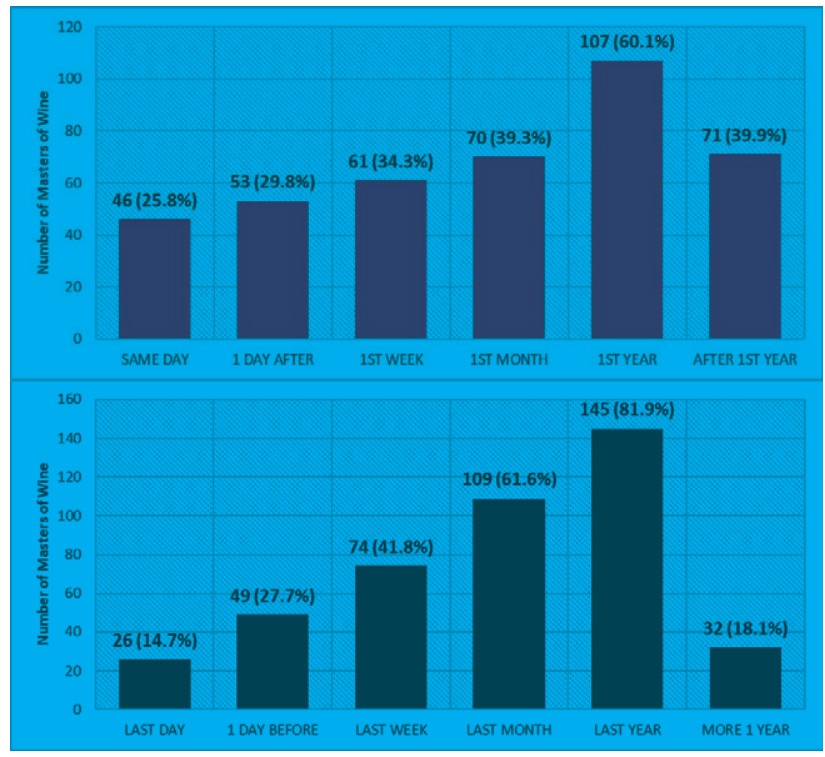

Figure 4. Publication activity: (top) Time elapsed since the creation of the Twitter account and the publication of the first tweet; (bottom) Time elapsed since the publication of the last tweet and the date of gathering data (12 May 2019). Source: Twitter. Note 1: each category is cumulative. That is, users tweeting the first day also tweeted within the first week, month, and so on. Likewise, users who tweeted last week also tweeted last month, year, and so on. Note 2: The time since last week was not available for one user.

The low influence of the time elapsed since the creation of the Twitter account may be due to the greater or lesser activity of the user when the account was set up. For example, $71 \mathrm{MWs}$ waited more than a year to post their first tweet (Figure 4; top) while only 70 published their first tweet during the first month. Similarly, 32 MWs did not publish a tweet over the last year as of when the time data was retrieved (Figure 4; bottom).

Table 5. Correlation matrix for user-level Twitter metrics.

\begin{tabular}{|c|c|c|c|c|c|c|c|}
\hline Variables & $\begin{array}{c}\text { Social } \\
\text { Authority }\end{array}$ & $\begin{array}{l}\text { Age } \\
\text { (days) }\end{array}$ & Tweets & Followers & Following & Favourites & Lists \\
\hline Social Authority & 1 & & & & & & \\
\hline Age (days) & 0.04 & 1 & & & & & \\
\hline Tweets & $* * 0.75$ & $* * 0.23$ & 1 & & & & \\
\hline Followers & ${ }^{* *} 0.65$ & ${ }^{* *} 0.28$ & ${ }^{* *} 0.82$ & 1 & & & \\
\hline Following & ${ }^{* *} 0.55$ & ${ }^{* *} 0.26$ & ${ }^{* *} 0.70$ & ${ }^{* *} 0.67$ & 1 & & \\
\hline Favourites & ${ }^{* *} 0.83$ & 0.03 & ${ }^{\star *} 0.70$ & ${ }^{* *} 0.61$ & $* * 0.61$ & 1 & \\
\hline Lists & $* * 0.55$ & ${ }^{* *} 0.39$ & ${ }^{\star *} 0.78$ & $* * 0.93$ & $* * 0.66$ & $* * 0.50$ & 1 \\
\hline
\end{tabular}

** Values are different from 0 with a significance level $\alpha<0.01$ Source: elaborated from Twitter data. 


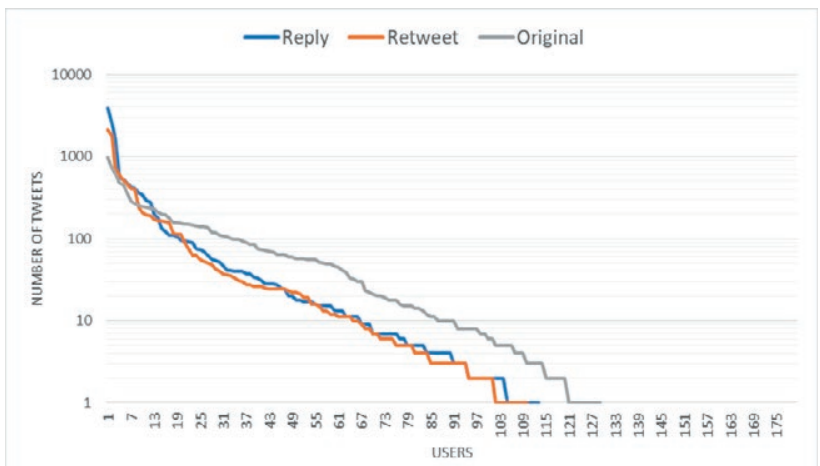

Figure 5. Distribution of publications (original tweets, replies and retweets). Source: elaborated from Twitter data.

\section{Publication-level data (Tweets)}

From October 2018 to April 2019, MWs published a total of 35,844 tweets, of which 14,517 (41\%) were replies, $10,817(30 \%)$ original tweets and 10,510 (29\%) retweets. The distribution of publications is skewed (Figure 5) and distinguishes two different pattern behaviours. A wide set of users who publish a moderate-to-low amount of tweets, especially original tweets on the one hand, and a small group of users (approximately 15) who publish a great number of original tweets, retweets and replies on the other hand.

The publication profile of each user can be determined upon the percentage of each type of publications: original tweets (creator), replies (commentator) and retweets (disseminator). This way, we can find users that all their tweets are original (strictly creators), users that only retweet other tweets (strictly disseminators), or any other combination.
Following this reasoning, authors designed a scale from 0 (any tweet published falls under one specific tweet type) to 5 (all tweets published fall under one specific tweet type) for each of the three publication types to characterise the publication pattern of each user. The threshold for each value of the scale is detailed below:

- Value 0: No tweets published on the corresponding typology.

- Value 1: from $1 \%$ to $25 \%$ of all tweets published fall under the corresponding typology.

- Value 2: from $26 \%$ to $50 \%$ of all tweets published fall under the corresponding typology.

- Value 3: from 51 to $75 \%$ of all tweets published fall under the corresponding typology.

- Value 4: from $76 \%$ to $99 \%$ of all tweets published fall under the corresponding typology.

- Value 5: all tweets published fall under the corresponding typology.

A total of 36 different publication patterns were identified, being those that did not publish any kind of content (strictly readers or ignorers) the category with the highest number of users (41 MWs; 23\%). 24 MWs were extremophile users (those with a 5 value in one dimension), 16 only published original tweets (strictly creators), 5 only published retweets (strictly disseminator) and 3 only published replies (strictly commentator). Other common profile patterns are characterised by combining a great percentage of original tweets and a low percentage of replies or retweets (Table 6).

The number of likes received by each tweet published in the period shows a skewed distribution (Figure 6), with few tweets attracting a significant number of likes and a long tail of tweets without any impact. The

Table 6. Publication profiles according to the type of tweet published.

\begin{tabular}{ccccl}
\hline & Class Type & & $\begin{array}{c}\text { Number } \\
\text { of MW }\end{array}$ & Profile \\
\hline Original & Reply & Retweet & & \\
\hline 0 & 0 & 0 & 41 & Strictly reader or ignorer. \\
5 & 0 & 0 & 16 & Strictly creator \\
3 & 1 & 1 & 13 & Moderate creator; very light commentator and disseminator \\
4 & 1 & 1 & 11 & Heavy creator; very light commentator and disseminator \\
2 & 2 & 1 & 10 & Light creator and commentator; very light disseminator \\
3 & 1 & 2 & 10 & Moderate creator; very light disseminator; light commentator \\
1 & 3 & 1 & 6 & Very light commentator; moderate creator; very light disseminator \\
2 & 3 & 1 & 6 & Light commentator; moderate creator; very light disseminator \\
0 & 0 & 5 & 5 & Strictly disseminator \\
1 & 1 & 3 & 5 & Very light creator; very light commentator; moderate disseminator \\
2 & 1 & 1 & 5 & Light creator; very light commentator and disseminator. \\
\hline
\end{tabular}

Source: elaborated from Twitter data. 


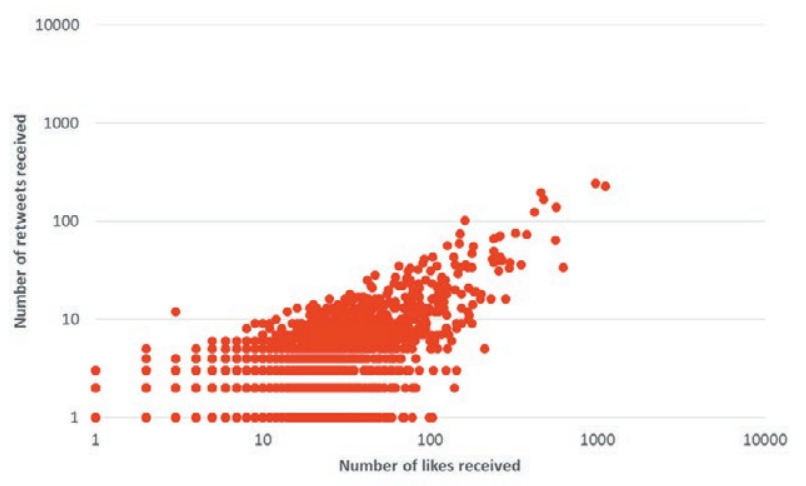

Figure 6. Scatterplot of the number of likes and retweets received by original tweets and replies. Source: elaborated from Twitter data.

original tweet with the highest number of likes received is posted by Jancin Robinson (1,113 likes). However, 25,112 (99.1\%) tweets (both original tweets and replies) receive less than 100 likes each, and only seven tweets receive more than 100 retweets each.

If we take the whole corpus of tweets published by MWs in the period (25,334 original tweets and replies), we can observe a great wealth of information in the embedded elements (Table 7): 6,602 hyperlinks, 11,819 hashtags, 39,206 users mentioned and 4,434 media (either photos or videos).

Mentions to other users constitute the most frequently used element (59.0\% of all tweets), followed by hyperlinks (25.4\%), hashtags (19.8\%) and media (17.5\%). However, this activity is highly skewed. For example, 82 users did not mention any user. Among the elements embedded in tweets, hashtags stand out as they can express interest in specific topics or terms. 4,169 different hashtags were located out of the 11,819 total hashtags extracted from the tweets (Table 8). The term \#wine is the most frequently used hashtag (634 times), by 46 different MWs from 10 different locations, followed by \#burgundy (used 138 times by 13 users). In addition, among the most used hashtags, some of them achieve higher impact (\#Winelife obtains an average of 14.3 likes per tweet), whilst others remain less popular ( \#cellartalk only 2.0 likes per tweet, being use almost the same number of times than \#Winelife).

The impact of tweets shows a dependence on the type of embedded element. The engagement rate (ER) (number of likes and retweets divided by the number of tweets) informs about the relative impact of tweets per user. On average, the ER of tweets including at least one media (10.9) is higher than the ER of tweets including at least one hashtag (7.6), hyperlink (5.0) or user mention (4.0).
Finally, the dissemination activity carried out by MWs on Twitter through retweets is also noteworthy. A total of 10,510 retweets have been identified in the period. $49.6 \%$ of retweets included at least one hyperlink, $42.0 \%$ included at least one user mention, $41.9 \%$ included media, and $34.0 \%$ included at least one hashtag.

The inclusion of embedded elements increases the engagement of tweets published by Masters of Wine. The average number of likes for those tweets with at least one embedded element is 5.3 whereas this same value for tweets without embedded elements is 2.2. Likewise, the average number of retweets received by tweets with at least one embedded element is 0.75 whereas this same value for tweets without embedded elements is 0.19 .

\subsection{Community}

14,953 tweets $(59.0 \%$ of all original tweets and replies analysed) contained a total of 39,206 user mentions. Of these, 2,990 (7.6\%) are mentions from one $\mathrm{MW}$ to another MW (Figure 7). Otherwise, $67 \mathrm{MWs}$ did not mention any other MW, and 20 did not receive any mention from another MW in the period analysed.

Given the number of Twitter profiles analysed (178), the generated network exhibits a low average Degree (16.6) and a low density (0.093). That is, the community of Masters of Wine is not intensively connected with each other through direct Twitter mentions. Consequently, the number of steps it takes on average to get from one user to another is high (network diameter is equal to 5).

Only few nodes (those located at the centre of the network) are highly connected to others, showing a higher centrality (prestige score). Natasha Hughes stands out as the MW who receives a greater number of mentions from other MWs (52), while Jancis Robinson is the MW who mentions other MWs the most (118 users). These two users also appear as the most influential MWs in the username-to-username mention network built. In absolute terms, Gorman McAdams (945 mentions) and Tim Atkin (1,932 mentions) are the MWs who have receive and provide the greatest number of mentions, respectively (Table 9). As regards the eigenvector centrality, Natasha Hughes stands out as the most influential user in the network.

A lack of reciprocity in the 'mentioning/mentioned' network is also identified, reflecting different profile usage and information interests. Few MWs are widely mentioned by others, but they rarely mention others. For example, John Downes was mentioned by 42 users and Eugene Mlynczyk by 39 MWs, but they did not mention any other MW. 
Table 7. Impact of tweets (original tweets and replies) according to the embedded elements: links, hashtags, user mentions and media.

\begin{tabular}{|c|c|c|c|c|c|c|}
\hline Media Embedded & Metric & Sum & Mean & Median & SD & Max \\
\hline Total & Tweets & 25334 & 140.7 & 17.0 & 473.5 & 4845 \\
\hline \multirow[t]{5}{*}{ Links } & Tweets & $\begin{array}{c}6446 \\
25.4 \%\end{array}$ & 35.8 & 4.0 & 76.8 & $\begin{array}{c}564 \\
\text { Jancis Robinson }\end{array}$ \\
\hline & Links & 6602 & 36.7 & 4.0 & 79.6 & $\begin{array}{c}618 \\
\text { Jancis Robinson }\end{array}$ \\
\hline & Likes & 42287 & 234.9 & 10.5 & 1155.0 & $\begin{array}{c}10836 \\
\text { Tim Atkin }\end{array}$ \\
\hline & Retweets & 8051 & 44.7 & 1.0 & 245.7 & $\begin{array}{c}2737 \\
\text { Tim Atkin }\end{array}$ \\
\hline & Engagement rate & NA & 5.0 & 2.7 & 5.5 & $\begin{array}{c}29.5 \\
\text { Derek Smedley }\end{array}$ \\
\hline \multirow[t]{5}{*}{ Hashtags } & Tweets & $\begin{array}{c}5007 \\
19.8 \%\end{array}$ & 27.8 & 3.0 & 63.5 & $\begin{array}{c}549 \\
\text { Christy Canterbury }\end{array}$ \\
\hline & Hashtags & 11819 & 71.2 & 5.0 & 207.4 & $\begin{array}{c}1755 \\
\text { Jeannie Cho Lee }\end{array}$ \\
\hline & Likes & 40626 & 225.7 & 12.0 & 956.0 & $\begin{array}{c}11591 \\
\text { Tim Atkin }\end{array}$ \\
\hline & Retweets & 5952 & 33.1 & 1.0 & 117.4 & $\begin{array}{c}1157 \\
\text { Tim Atkin }\end{array}$ \\
\hline & Engagement rate & NA & 7.6 & 4.1 & 9.4 & $\begin{array}{c}63.0 \\
\text { Amy Christine }\end{array}$ \\
\hline \multirow[t]{5}{*}{ @ } & Tweets & $\begin{array}{l}14953 \\
59.0 \%\end{array}$ & 83.1 & 10.0 & 242.8 & $\begin{array}{c}2401 \\
\text { Tim Atkin }\end{array}$ \\
\hline & User mentions & 39206 & 217.8 & 19.0 & 677.0 & $\begin{array}{c}6700 \\
\text { Tim Atkin }\end{array}$ \\
\hline & Likes & 57586 & 319.9 & 19.0 & 1119.8 & $\begin{array}{c}12800 \\
\text { Tim Atkin }\end{array}$ \\
\hline & Retweets & 8032 & 44.6 & 3.0 & 173.7 & $\begin{array}{c}2042 \\
\text { Tim Atkin }\end{array}$ \\
\hline & Engagement rate & NA & 4.0 & 3.0 & 3.2 & $\begin{array}{c}16.0 \\
\text { David Hesketh }\end{array}$ \\
\hline \multirow[t]{4}{*}{ Media } & Tweets & $\begin{array}{c}4434 \\
17.5 \%\end{array}$ & 24.6 & 1.0 & 53.5 & $\begin{array}{c}311 \\
\text { Greg Sherwood }\end{array}$ \\
\hline & Likes & 51263 & 284.8 & 3.0 & 1085.7 & $\begin{array}{c}11632 \\
\text { Tim Atkin }\end{array}$ \\
\hline & Retweets & 7622 & 42.3 & 0.0 & 155.4 & $\begin{array}{c}1276 \\
\text { Tim Atkin }\end{array}$ \\
\hline & Engagement rate & NA & 10.9 & 7.5 & 11.2 & $\begin{array}{c}65.9 \\
\text { Jancis Robinson }\end{array}$ \\
\hline
\end{tabular}

Source: elaborated from Twitter data.

Other MWs can be distinguished by mentioning other colleagues, but they rarely receive mentions from other MWs. For example, Tim Atkin mentioned 114 MWs but he only received mentions from 21 MWs. Jancis Robinson mentioned 118 MWs but she only received mentions from 27.

It is also noteworthy to comment that some MWs (specifically 121) also mention other MWs without a Twitter account, through their real name. This way, 107 MWs not present on Twitter have been mentioned at least once, accumulating a total of 603 mentions. Julia Harding (49 mentions) is the most mentioned MW without a Twitter profile by other MWs (Table 10).

\section{DISCUSSION AND CONCLUSIONS}

Since not all tweets published by MWs have been analysed, results should be taken cautiously as seasonal effects or changes in publication patterns might happen. 
Table 8. Most frequently hashtags used by Masters of Wine.

\begin{tabular}{lccccccl}
\hline Hashtag & $\begin{array}{c}\text { Times } \\
\text { used }\end{array}$ & $\begin{array}{c}\text { Avg. } \\
\text { likes }\end{array}$ & $\begin{array}{c}\text { Avg. } \\
\text { retweets }\end{array}$ & $\begin{array}{c}\text { Number } \\
\text { of users }\end{array}$ & $\begin{array}{c}\text { Users } \\
(\%)\end{array}$ & $\begin{array}{c}\text { Number } \\
\text { of countries }\end{array}$ & Countries \\
\hline \#Wine & 634 & 10.4 & 1.9 & 46 & 25.8 & 10 & $\begin{array}{l}\text { Australia, Canada, Greece, Hong Kong, India, Ireland, New } \\
\text { Zealand, Sweden, UK, US }\end{array}$ \\
\#Burgundy & 138 & 12.6 & 2.1 & 13 & 7.3 & 5 & Hong Kong, India, Ireland, UK, US \\
\#masterofwine & 120 & 12.2 & 2.5 & 12 & 6.7 & 6 & Australia, Canada, Hong Kong, India, UK, US \\
\#Cellartalk & 120 & 2.0 & 0.4 & 2 & 1.1 & 2 & Australia, New Zealand \\
\#Winelife & 119 & 14.3 & 2.9 & 4 & 2.2 & 4 & Hong Kong, India, UK, US \\
\#Winetasting & 114 & 12.2 & 2.4 & 11 & 6.2 & 6 & Australia, Hong Kong, India, Ireland, UK, US \\
\#malbecargentino & 111 & 6.1 & 1.7 & 1 & 0.6 & 1 & US \\
\#malbecworldday & 107 & 6.6 & 2.0 & 1 & 0.6 & 1 & US \\
\#Mwtour & 103 & 5.7 & 0.5 & 13 & 7.3 & 6 & India, Netherlands, New Zealand, South Africa, UK, US \\
\#mastersofwine & 95 & 6.6 & 0.8 & 17 & 9.6 & 9 & France, Hong Kong, India, Ireland, Netherlands, South \\
& & & & & & & Africa, Spain, UK, US
\end{tabular}

Source: elaborated from Twitter data. Note: no local language equivalents aggregated.

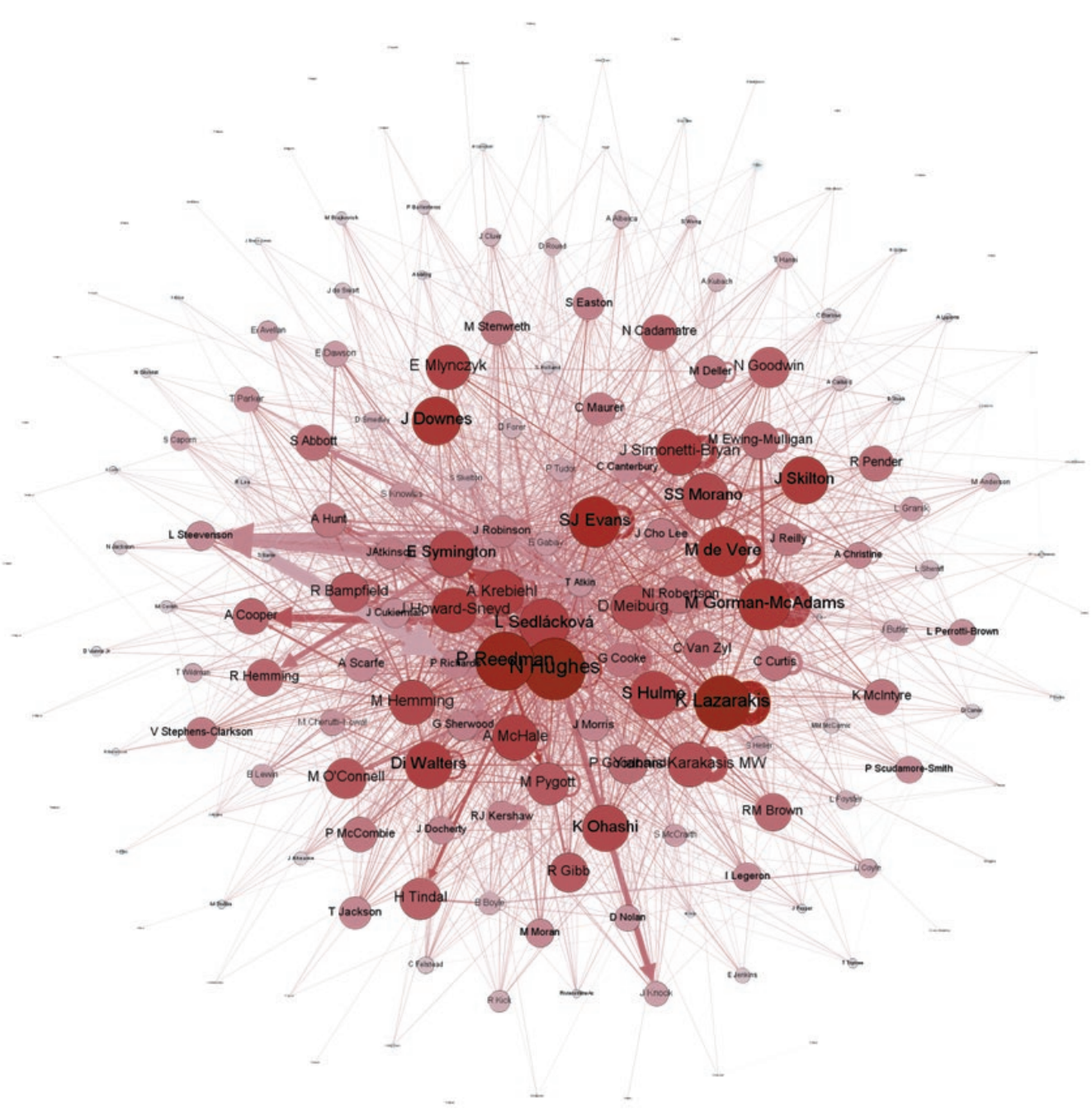

Figure 7. User mentions network for Masters of Wine. Source: Elaborated from Twitter data and generated with Gephi. 
Table 9. Most influential Masters of Wine in the username-to-username mention network through node-level metrics (InDegree, OutDegree, Eigenvector centrality).

\begin{tabular}{|c|c|c|c|c|c|c|c|}
\hline \multicolumn{3}{|c|}{ InDegree } & \multicolumn{3}{|c|}{ OutDegree } & \multicolumn{2}{|l|}{ Eigenvector } \\
\hline MW & Users & Mentions & MW & Users & Mentions & MW & Users \\
\hline N Hughes & 52 & 492 & J Robinson & 118 & 1846 & N Hughes & 1.0 \\
\hline P Reedman & 50 & 442 & T Atkin & 114 & 1932 & P Reedman & 0.94 \\
\hline SJ Evans & 45 & 345 & N Hughes & 88 & 659 & K Lazarakis & 0.90 \\
\hline M Gorman-McAdams & 42 & 945 & A Krebiehl & 86 & 585 & M Gorman-McAdams & 0.83 \\
\hline J Downes & 42 & 109 & E Gabay & 80 & 892 & SJ Evans & 0.82 \\
\hline
\end{tabular}

Table 10. Masters of Wine without a Twitter profile most mentioned on Twitter by other Masters of Wine.

\begin{tabular}{lc}
\hline Most mentioned & Mentions \\
\hline Julia Harding & 49 \\
Caroline Gilby & 25 \\
Olivier Humbrecht & 24 \\
Michael Broadbent & 23 \\
Liz Thach & 23 \\
Patrick Schmitt & 21 \\
Jean-Michel Valette & 19 \\
Mark Andrew & 14 \\
Steve Smith & 13 \\
David Gleave & 12 \\
\hline
\end{tabular}

Notwithstanding, the set of 35,653 tweets published over seven months of activity is considered representative enough to estimate the recent activity of MWs.

Another aspect to take into account is the level of Twitter adoption. The current total number of active users amounts to 330 million [14], showing a decrease with respect to 2018 (336 million users). Given the bias of MW origin towards the US and the UK, the penetration of Twitter in these countries is critical. In 2019, the US had 48.5 million users ( $14.7 \%$ of the total population), being the country with the highest number of active Twitter users in the World. The UK had 13.7 million users (20.2\% of the total population), being the 4 th country in the ranking [15].

The percentage of wine drinkers in these countries should also influence the results obtained. As a proxy - and considering the last data available from the International Organisation of Vine and Wine (which corresponds to 2018) - the consumption of wine was 12.4 litres per capita ( 15 years of age or older) in United States (39th in the world), and 22.6 litres per capita (15 years of age or older) in the United Kingdom (23rd in the world) 5 .

\footnotetext{
${ }^{5}$ https://www.oiv.int/en/statistiques/recherche
}

Besides Twitter demographics, Wilson and Quinton [43] detected an elevated occurrence of some specific wine type mentions (brands, red/white, places, champagne/sparling). Our study corroborates the use of these terms through hashtags, specifically of locations (\#hongkong, \#napavalley, \#london, \#chile, \#edinburgh, \#argentina, \#baden, \#italy, \#california, etc.), brands and varietals (\#burbundy, \#malbecargentino, \#bordeaux, \#champagne, \#garnachagrenache, \#pinotnoir, \#cabernetsauvignon, \#chardonnay, etc.), denominations of origin (\#bordeaux, \#rioja, etc.), and terms related with leisure time (\#tasting, \#travel, \#delicious, \#familytime, \#holiday, etc.).

The results evidence a low presence of MWs on Twitter (48.4\% of all individuals awarded), although higher for recent awardees. They predominantly speak in English, include hyperlinks to promote their related websites and come from Anglo-Saxon countries (UK, US and Australia). The fact that a significant number of MWs includes the term 'MW' in their Twitter username denotes a potential interest in using the profile for selfpromotion, giving the MW qualification an influential status.

Master of Wine's Twitter profiles attract a significant number of followers on average. However, their social activity (following other users) is further limited (only 43 MWs follow more than 1,000 users), which also indicates an interest primarily oriented towards promotion rather than conversation. The long average time elapsed since the creation of the accounts to the first published tweet might reveal on average there is a weak interest in the strategic use of Twitter.

The publication activity is varied in the period and no single activity pattern is detected, being the passive user the most frequent kind. Otherwise, the most productive users are likely to publish more replies and retweets.

Given the number of followers that MWs have on average, impact (measured according to the number of likes and retweets received) is low. Even though the engagement rate of tweets increases by adding sup- 
plementary embedded elements, including hyperlinks, hashtags and media is less common, while mentioning other users is more frequent.

A Social Authority below 25 (out of 100) can be considered low. While values over 90 points are reserved for famous people (e.g., the singer Justin Bieber, entrepreneur Elon Musk, or US President Donald Trump ${ }^{6}$ have a social authority of 100), values from 50 to 75 points can be considered significant for specific market domains. For example, in the case of the wine market, the wellknown wine critic Robert Parker exhibits a Social Authority of 40 as of November 2020. This value was 54 in March 2018 [16], which shows the volatility of prestige, as followers can vary over time.

$37 \%$ of the MWs obtain a Social Authority score lower than 25. Therefore, impact (measured according to the followers' Social Authority) is on average low. Despite the total number of followers attracted being elevated, the authority of these followers is limited, except for a few users.

Further research on followers' linkage to the industry might reveal whether MWs relate to influential people in the wine industry on Twitter.

Despite MWs frequently mentioning other users, they rarely mention other MWs, as the low-density userto-user network demonstrates. Moreover, a lack of reciprocity in user mentions is identified, where a few MWs mention many awardees in their tweets, but the vast majority of these do not mention other MWs.

The general findings of this work show MWs on Twitter as high attractors (as regards the number of followers they attain), moderate publishers (as regards the quantity of original content published), moderate influencers (as regards the reactions to their published content), low connectors (as regards the users they follow) and low interactors (as regards the number of mentions to other MWs).

Given the reputation and influence of MWs in the wine industry, especially in English-speaking countries, these findings reveal that this actor (community of people awarded with the MW accreditation) is not using Twitter to gain or reinforce this reputation or influence. This research also shows that this community is very heterogeneous on this social network and that some of their components are very active. In any case, and given the uneven geographical distribution of MWs, these results would be especially significant in countries where the MW qualification is more integrated in the wine business culture (United Kingdom, United States and Australia).

${ }^{6}$ Donald Trump's Twitter account was suspended in January 2021. https://blog.twitter.com/en_us/topics/company/2020/suspension.html
If we consider the earlier findings by Wilson and Quinton [43], who detected a low engagement of wine marketers, brands and retailers on Twitter, we can reinforce the hypothesis that the influence space provided by Twitter to the wine sector is being occupied by consumers and amateurs, who can easily connect and engage with other consumers. This may cause a loss of representativeness on the part of professional wine experts involved in the communication of wine trust attributes signals. These results are of importance both for the industry and the markets, where expert opinion is very important, but their influence is due to a combination of expertise and communication strategy. In any case, future research analysing other wine-focused Twitter groups is advisable for a better understanding of the results obtained.

Given the rising importance of online sales channels in the wine sector, increased by the COVID-19 crisis [22], the effective use of social media in general and Twitter in particular by the professional actors of this industry should be considered as a strategic issue of central importance.

This research does not attempt to strictly identify influencers (as this term refers to the extent to which peers exert influence on the attitudes, thoughts and actions of an individual), which is one step beyond the description of publication patterns. Similarly, the dynamics of the 'sense of community' force of MWs on Twitter is outside the scope of this study, as it needs four characteristics (belonging, influencing, supporting and sharing) to be completely established [28]. A deeper analysis on MW followers as well as a content analysis of published tweets is consequently advisable for future works focusing on the characterisation of the MW online community.

Finally, future research should also delve into the use of other social platforms (e.g., Instagram and Facebook) by all professional actors in the wine sector, as well as to ascertain the reasons for using (or not using) these social networking tools.

\section{ACKNOWLEDGEMENTS}

This work has been supported by the eMarketwine project (CS02016-78775-R), funded by the Ministry of Economy and Competitiveness (MINECO) in Spain. The authors sincerely appreciate the work carried out by the two anonymous reviewers, who have helped to improve the manuscript in a remarkable way. 


\section{REFERENCES}

[1] Albright, A., Pedroni, P., Sheppard, S., 2018. Uncorking Expert Reviews with Social Media: A Case Study Served with Wine. https://web.williams. edu/Economics/wp/UncorkingExpertReviews.pdf (accessed 12 June 2020).

[2] Ali, H. H., Lecocq, S., Visser, M., 2010. The impact of gurus: Parker grades and en primeur wine prices. Journal of wine economics, 5(1), 22-39. https:// doi.org/10.1017/s1931436100001358

[3] Anger, I., Kittl, C., 2011. Measuring influence on Twitter. In: Proceedings of the 11th international conference on knowledge management and knowledge technologies, September 7-9. Graz, Austria. https://doi.org/10.1145/2024288.2024326

[4] Ashton, R. H., 2016. The value of expert opinion in the pricing of Bordeaux wine futures. Journal of Wine Economics, 11(2), 261-288. https://doi. org/10.1017/jwe.2016.6

[5] Bhattacharya, P., Zafar, M.B., Ganguly, N., Ghosh, S., Gummadi, K.P., 2014. Inferring user interests in the Twitter social network. In: Proceedings of the 8th ACM Conference on Recommender systems, October 6-10. California, United States. https://doi. org/10.1145/2645710.2645765

[6] Bakshy, E., Hofman, J.M., Mason, W.A., Watts, D.J., 2011. Everyone's an influencer: quantifying influence on Twitter. In: Proceedings of the fourth ACM international conference on Web search and data mining, February 9-11. Hong Kong, China. https://doi.org/10.1145/1935826.1935845

[7] Barabási, A.L., 2016. Network science. Cambridge university press, UK.

[8] Beninger, S., Parent, M., Pitt, L., Chan, A., 2014. A content analysis of influential wine blogs. International Journal of Wine Business Research, 26(3), 168-187. https://doi.org/10.1108/ijwbr-09-2013-0036

[9] Boyd, D.M., Ellison, N.B., 2007. Social network sites: Definition, history, and scholarship. Journal of computer-mediated Communication, 13(1), 210-230. https://doi.org/10.1109/emr.2010.5559139

[10] Burton, S., Soboleva, A., 2011. Interactive or reactive? Marketing with Twitter. Journal of consumer marketing, 28(7), 491-499. https://doi. org/10.1108/07363761111181473

[11] Capitello, R., Agnoli, L., Begalli, D., Codurri, S., 2014. Social media strategies and corporate brand visibility in the wine industry: Lessons from an Italian case study. EuroMed Journal of Business, 9(2), 129-148. https://doi.org/10.1108/emjb-10-2013-0046
[12] Cha, M., Haddadi, H., Benevenuto, F., Gummadi, K.P., 2010. Measuring user influence in Twitter: The million follower fallacy. In: Proceedings of the Fourth International AAAI Conference on Weblogs and Social Media, May 23-26. Washington DC, United States. https://www.aaai.org/ocs/index. php/ICWSM/ICWSM10/paper/viewFile/1538/1826 (accessed 12 June 2020).

[13] Chocarro, R., Cortiñas, M., 2013. The impact of expert opinion in consumer perception of wines. International Journal of Wine Business Research, 25(3), 227-248. https://doi.org/10.1108/ijwbr-2012-0014

[14] Clement, J., 2019a. Twitter: number of monthly active users (2010-2019). https://www.statista.com/ statistics/282087/number-of-monthly-active-twitter-users (accessed 12 June 2020).

[15] Clement, J., 2019b. Countries with the most Twitter users 2019. https://www.statista.com/statistics/242606/number-of-active-twitter-users-inselected-countries (accessed 12 June 2020).

[16] Compés-López, R., Font-Julian, C., Orduna-Malea, E., 2018. Has Robert Parker lost his hegemony as a prescriptor in the wine World? A preliminar inquiry through Twitter. In: 2nd International Conference on Advanced Research Methods and Analytics, July 12-13. Valencia, Spain. https://doi. org/10.4995/carma2018.2018.8320

[17] Cosenza, Tracy R., Solomon Michael R., Kwon, W-S., 2015. Credibility in the Blogosphere: A Study of Measurement and Influence of Wine Blogs as an Information Source. Journal of Consumer Behaviour, 14(2), 71-91. https://doi.org/10.1002/cb.1496

[18] Costopoulou, C., Ntaliani, M., Ntalianis, F., 2018. Social Media in Greek and German Wineries' Websites. In: 9th International Conference on Information, Intelligence, Systems and Applications (IISA 2018), July 23-25. Zakynthos, Greece. https://doi. org/10.1109/iisa.2018.8633596

[19] Costopoulou, C., Ntaliani, M., Ntalianis, F., 2019. An Analysis of Social Media Usage in Winery Businesses. Advances in Science, Technology and Engineering Systems, 4(4), 380-387. https://doi. org/10.25046/aj040446

[20] Dewald, B. B., 2008. The role of the sommeliers and their influence on US restaurant wine sales. International Journal of Wine Business Research, 20(2), 111-123. https://doi. org/10.1108/17511060810883740

[21] Eftekhar, M., Koudas, N., 2013. Some Research Opportunities on Twitter Advertising. IEEE Data Eng. Bull., 36(3), 77-82. http://sites.computer.org/ debull/A13sept/p77.pdf (accessed 12 June 2020). 
[22] EUAWE, 2020. Behaviour of European wine consumers during the lockdown. http://www.euawe. $\mathrm{com} / \mathrm{wp}$-content/uploads/2020/05/EuAWEINSEEC-Survey-Behaviour-of-European-wine-consumers-during-the-lockdown.pdf (accessed 12 June 2020).

[23] Laverie, D.A., Humphrey, W.F., Velikova, N., Dodd, T.H., Wilcox, J.B., 2011. Building wine brand communities with the use of social media: A conceptual model. In: Proceedings of the 6th AWBR International Conference, 9-11 June. Bordeaux, France. http://academyofwinebusiness.com/wp-content/ uploads/2011/09/71-AWBR2011_Laverie_Humphrey_Velikova_Dodd_Wilcox.pdf (accessed 12 June 2020).

[24] Leigon, B., 2011. Grape/Wine Marketing with New Media and Return of the Boomer. Practical Winery \& Vineyard Journal, San Rafael.

[25] Lockshin, L., Corsi, A.M., 2012. Consumer behavior for wine 2.0: A review since 2003 and future directions. Wine Economics and Policy, 1(1), 2-23. https://doi.org/10.1016/j.wep.2012.11.003

[26] Marlowe, B., Brown, E.A., Schrier, T., Zheng, T., 2017. Beverage bloggers: A developing relationship between wine blogger expertise and twitter followers. International Journal of Hospitality Beverage Management, 1(1), 1-20. https://doi. org $/ 10.34051 / \mathrm{j} / 2019.2$

[27] Masset, P., Weisskopf, J. P., Cossutta, M., 2015. Wine tasters, ratings, and en primeur prices. Journal of Wine Economics, 10(1), 75-107. https://doi. org/10.1017/jwe.2015.1

[28] McMillan, D.W., Chavis, D.M., 1986. Sense of community: a definition and theory. Journal of Community Psychology, 14(1), 6-23. https://doi. org/10.1002/1520-6629(198601)14:1\%3C6::aidjcop2290140103\%3E3.0.co;2-i

[29] Newman, K., 2010. How wine lovers use social media: Wine and social media have created an incredible force within the industry. Wine Enthusiast. https://www.winemag.com/2010/02/17/howwine-lovers-use-social-media/ (accessed 12 June 2020).

[30] Orduna-Malea, E., Alonso-Arroyo, A., 2017. Cybermetric techniques to evaluate organizations using web-based data. Elsevier, UK.

[31] Ovadia, S., 2009. Exploring the potential of Twitter as a research tool. Behavioral \& Social Sciences Librarian, 28(4), 202-205. https://doi. org/10.1080/01639260903280888

[32] Pucci, T., Casprini, E., Nosi, C., Zanni, L., 2019. Does social media usage affect online purchasing intention for wine? The moderating role of subjective and objective knowledge. British Food Journal, 121(2), 275-288. https://doi.org/10.1108/bfj-062018-0400

[33] Riquelme, F., González-Cantergiani, P., 2016. Measuring user influence on Twitter: A survey. Information Processing \& Management, 52(5), 949-975. https://doi.org/10.1016/j.ipm.2016.04.003

[34] Rod, M., Ellis, N., Beal, T., 2012. Discursive constructions of the role of cultural intermediaries in the wine markets of Japan and Singapore. Qualitative Market Research: An International Journal, 15(2), 128-147. https://doi. org/10.1108/13522751211215868

[35] Sigala, M., Haller, C., 2019. The Impact of Social Media on the Behavior of Wine Tourists: A Typology of Power Sources, in Sigala, M. and Robinson, R.N.S. (Eds.), Management and Marketing of Wine Tourism Business. Palgrave Macmillan, Cham, Switzerland, 139-154. https://doi.org/10.1007/9783-319-75462-8_8

[36] Storchmann, K., 2018. Wine Economics, in Ashenfelter, O., Gergaud, O., Storchmann, K. and Ziemba, W. (Eds.), Handbook of the economics of wine. World Scientific Publishing, Singapore, 3-40. https://doi.org/10.1142/9789813232747_0001

[37] Szolnoki, G., Dolan, R., Forbes, S., Thach, L., Goodman, S., 2018. Using social media for consumer interaction: An international comparison of winery adoption and activity. Wine Economics and Policy, 7(2), 109-119. https://doi.org/10.1016/j. wep.2018.07.001

[38] Thach, L., 2009. Wine 2.0-The next phase of wine marketing? Exploring US winery adoption of wine 2.0 components. Journal of wine research, 20(2), 143-157. https://doi. org/10.1080/09571260903169548

[39] Thach, L., Lease, T., Barton, M., 2016. Exploring the impact of social media practices on wine sales in US wineries. Journal of Direct, Data and Digital Marketing Practice, 17(4), 272-283. https://doi. org/10.1057/dddmp.2016.5

[40] Watson, Q., 2011. Social media increases wine sales and consumption. Polytechnic State University, CA, United States. https://digitalcommons.calpoly.edu/ cgi $/$ viewcontent.cgi $?$ article $=1072 \&$ context $=$ agbsp (accessed 12 June 2020).

[41] Williams, S. A., Terras, M. M., Warwick, C., 2013. What do people study when they study Twitter? Classifying Twitter related academic papers. Journal of Documentation, 69(3), 384-410. https://doi. org/10.1108/jd-03-2012-0027 
[42] Wei, W., Cong, G., Miao, C., Zhu, F., Li, G., 2016. Learning to find topic experts in twitter via different relations. IEEE Transactions on Knowledge and Data Engineering, 28(7), 1764-1778. https://doi. org/10.1109/tkde.2016.2539166

[43] Wilson, D., Quinton, S., 2012. Let's Talk about Wine: Does Twitter Have Value? International Journal of Wine Business Research, 24(4), 271-286. https://doi.org/10.1108/17511061211280329

[44] Wright, A., 2015. Lifestyle Blogging Report. Wine Bloggers Conference, Penticton, BC.

[45] Zimmer, M., Proferes, N., 2014. A topology of Twitter research: disciplines, methods, and ethics. Aslib Journal of Information Management, 66(3), 250-261. https://doi.org/10.1108/AJIM-09-20130083 